\title{
Sexual selection on multivariate phenotype in wild and mass-reared Ceratitis capitata (Diptera: Tephritidae)
}

\author{
MS Rodriguero ${ }^{1}, \mathrm{MT}_{\text {Vera }}{ }^{2}, \mathrm{E} \mathrm{Rial}^{4}, \mathrm{~J}^{\mathrm{P}} \mathrm{Cayol}^{3}$ and JC Vilardi ${ }^{1,5}$ \\ ${ }^{1}$ Laboratorio de Genética de Poblaciones, Depto. Ecología, Genética y Evolución, Fac. Cs. Exactas y Naturales, Univ. Buenos Aires,

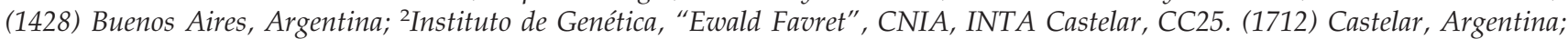 \\ ${ }^{3}$ International Atomic Energy Agency. Wagramerstrasse 5, PO Box 100. A-1400 Vienna. Austria; ${ }^{4}$ Fundación Barrera \\ Zoofitosanitaria Patagónica, Argentina
}

\begin{abstract}
Males with a larger thorax and narrower face were found to be favoured by directional sexual selection in a previous field cage experiment where Ceratitis capitata males from the Seib 6-96 genetic sexing strain competed with wild males from Alto Valle (Patagonia) for the possession of wild females. Targets of sexual selection, however, might differ between wild and laboratory females as a response to adaptation to mass-rearing conditions. To evaluate possible divergences on the targets of sexual selection as a by-product of adaptation to mass-rearing conditions, field cage tests were performed with both wild and laboratory females. To avoid possible bias due to correlation among the measured traits (eye length [EL], face width [FW], head width $[\mathrm{HW}]$, and thorax length $[\mathrm{TL}])$, a multivariate analysis was applied. Consistent with the previous experiment, the results
\end{abstract}

indicated that TL and FW are probable targets of directional sexual selection independently of female strain. However, laboratory females were less selective than wild ones. Additionally, correlational sexual selection was detected acting on the multivariate phenotype. The effects of correlational selection overlap with those of directional selection on each single trait. The analysis of mating pair characteristics showed patterns that do not match the expectations for a random mating system. The current analysis indicates that during mating pair formation two processes overlap. On the one hand, sexual selection favours males with larger size (TL) and narrower faces (FW). This effect occurs in both wild and laboratory females. In addition, assortative mating based on both phenotype and origin was also observed.

Heredity (2002) 89, 480-487. doi:10.1038/sj.hdy.6800170

Keywords: female choice; morphometric traits; genetic sexing strains; correlational selection; assortative mating; Ceratitis capitata

\section{Introduction}

Darwin (1871) used the term sexual selection to explain the evolution of elaborate male characters that are apparently detrimental under natural selection. Two different kinds of evolutionary processes can account for the evolution of such traits (Partridge and Halliday, 1984; Møller, 1994): intrasexual selection or competition for mates between members of the same sex, usually males, and intersexual selection, that involves active choice of particular individuals of the opposite sex, usually female choice of mates. These categories form a continuum (Boake et al, 1996) and it is not always easy to determine which form of selection is acting on a particular trait (Partridge and Halliday, 1984; Møller, 1994; Whittier et al, 1994).

In many species body size was often found to be positively correlated with male mating success (see Partridge and Halliday, 1984). However, such an association might

Correspondence: Dr JC Vilardi, Depto. Ecología, Genética y Evolución, Facultad de Ciencias Exactas y Naturales, Universidad de Buenos Aires. (1428) Buenos Aires, Argentina. E-mail: vilardi@tutopia.com

${ }^{5}$ Member of Carrera del Investigador Cientifico, CONICET, Argentina

Received 4 January 2002; accepted 28 July 2002 be indirect, ie the direct target of selection might be one or several size-related traits. The mechanisms responsible for consistent relationships between any particular trait and sexual selection are not well understood, and might be related with characteristics of the mating behaviour.

The Mediterranean fruit fly, Ceratitis capitata, is a useful model to analyse the relationship between size-related traits and sexual selection. This species displays a lek mating system (Prokopy and Hendrichs, 1979; Whittier et al, 1992). Male aggregations occur on the bottom surface of leaves where they produce a pheromone call to attract females (Whittier et al, 1994). After females' arrival the male begins to perform a complex courtship involving also visual and acoustical stimuli (Féron, 1962; Webb et al, 1983; Calcagno et al, 1999, 2002; Eberhard, 2000). The common finding that mating success is highly variable among lekking males has led to the predominant view that mate choice is an important component of sexual selection in lek-mating systems (eg, Whittier et al, 1994; Jones et al, 1998). However, many traits can be correlated with mating success without being necessarily matechoice targets (Norry et al, 1999). Besides, aggressive interactions between males or male activity levels to attempt copulation are probably intrasexually selected traits in many lek-mating species. However, C. capitata males only weakly defend their territories, and there is 
no evidence of a relationship between territory location and mating success (Whittier et al, 1992, 1994).

Ceratitis capitata is a major agricultural pest managed through control programmes that involve the Sterile Insect Technique (Knipling, 1955). The optimisation of this method requires an understanding of the type of mating system and a good knowledge of sexual selection mechanisms (Liedo Fernández, 1997). Laboratory (hereafter lab) strains may possess behavioural and physiological traits that diverge from those required for mating success by wild populations (Cayol, 2000). Particularly, mass-reared females become receptive at a much earlier age (eg, Rössler, 1975; Wong and Nakahara, 1978) and are less selective than wild ones (Zapien et al, 1983; Kaneshiro et al, 1990; Calkins, 1991). Additionally, crowded conditions preclude the formation of leks (Cayol, 2000). The process of adaptation to mass-rearing conditions may also result in genetic differences between lab and wild flies. Therefore, behavioural differences between lab and wild flies are the consequences of both environmental and genetic factors (Eberhard, 2000), and in field conditions they may lead to a different ability to compete for mating (sexual selection) and/or assortative mating.

Mating success in C. capitata is determined by factors such as morphology (Churchill Stanland et al, 1986; Hunt et al, 1998; Norry et al, 1999; Orozco and López, 1993; Rodriguero et al, 2002), nutritional level (Blay and Yuval, 1997), and behaviour (Calcagno, 1999, 2002). To date, there is very little information, if any, about the occurrence of assortative mating based on morphology, even though there is evidence of departures from random mating respect to strain (eg, Zapien et al, 1983; McInnis et al, 1996).

Analysing video recorded courtships of lab and wild medflies Norry et al (1999) were able to detect intersexual selection on morphometric traits. In a previous work under field cage conditions (Cayol et al, 1999) male competitiveness and sexual compatibility between wild medflies from Patagonia (Argentina) and a mass-rearing strain (Seib 6-96) were evaluated. In cages where wild and lab males competed for mating with wild females only (unisexual tests) Rodriguero et al (2002) observed the occurrence of sexual selection on some size-related traits.

In the present work we analysed sexual selection and assortative mating in bisexual tests involving the same strains as in those by Cayol et al (1999) and Rodriguero et al (2002). In this case wild and lab males competed for mating in cages where both wild and lab females were available as mating partners. The aim of the present work was to examine the occurrence of assortative mating and the possibility that sexual selection targets were female strain dependent

\section{Materials and methods}

\section{Biological materials}

The lab strain used in this work was the Seib 6-96, which carries a white pupae ( $w p)$ mutation (Rössler, 1979). A translocation $\mathrm{T}(\mathrm{Y}: 5)$ 2-22 (Franz et al, 1994) produces females with a white puparium and wild type male puparium, enabling to sort sexes at this stage. The lab pupae were produced at the BioKm8 facility (Mendoza, Argentina). They were irradiated in hypoxia $2 \mathrm{~d}$ before

emergence ("IMCO 20" $\mathrm{Co}^{60}$ irradiator, minimum absorbed dose $=100 \mathrm{~Gy}$, maximum absorbed dose $=150$ Gy) and packed and sent to testing area, in northern Argentina.

Wild flies were collected from infested figs and peaches from Alto Valle Region, Patagonia, Argentina. Fruits collected in the field and backyards were taken to the lab and placed in trays on sand litter. Sand was checked periodically to collect wild pupae, which were then carried to the testing area. Once at the testing site pupae were placed in flasks until emergence. Virgin adults were aspirated from the flask within $24 \mathrm{~h}$ after emergence in order to separate the sexes. Once sexed, the flies were kept in separate rooms until they reached sexual maturity at the age of 6-8 days for lab flies and 8-10 days for wild flies.

\section{Field cage tests}

The test was carried out at Estación Experimental Agroindustrial Obispo Colombres, Tucumán, Argentina. Outdoor cylindrical field cages $(2.0 \mathrm{~m}$ high and $2.9 \mathrm{~m}$ diameter, Saran screen 20 by 20 mesh) (Calkins and Webb, 1983) with a young lemon tree were used to score male mating success under a mass selection experiment. Individuals from different strains were identified with the addition of a water-based paint dot on their notothorax. Each test consisted of the release of 30 wild males and 30 lab sterile males at dawn, about 7.00 am local time. Half an hour later, 30 wild females and 30 lab sterile females were released into the cage. During a 7-h observation period, mating pairs (successful) were scored and gently removed with the aid of a vial from the cage as they formed. Strain origin was determined for both male and female and couples were placed in the shade until the end of copulation. Couples were individually labelled. Males which were not able to copulate along the test were labelled as 'unsuccessful'. This is a heterogeneous group involving individuals that were not able to integrate to any lek, moved from lek to lek or stayed inside the same lek throughout the whole observation period. They were collected altogether in a single vial.

\section{Morphometric analyses}

From a total of 2520 flies, 191 successful couples and 189 unsuccessful males, were selected at random and measured for four body size related traits: eye length (EL), face width (FW), head width (HW), thorax length (TL) (Figure 1 ). These traits were chosen because in previous works (Norry et al, 1999; Rodriguero et al, 2002) they gave evidence of sexual selection acting on multivariate phenotype. All measurements were performed, by the same observer, with a binocular microscope fitted with an ocular micrometer (1 ocular unit $=0.0125 \mathrm{~mm}$ for $\mathrm{EL}$ and FW, measured at $100 \times$ magnification; 1 ocular unit $=$ $0.0250 \mathrm{~mm}$ for HW and TL, measured at $50 \times$ magnification). To measure HW and EL, the head was removed and observed from the front. TL was scored from lateral view.

\section{Data analyses}

All measurements were standardised to have mean zero and unit variance for each cage before the analyses. Phenotypic correlations between traits were estimated by the Spearman rank correlation test. Correlation among characters complicate the measurement of phenotypic 


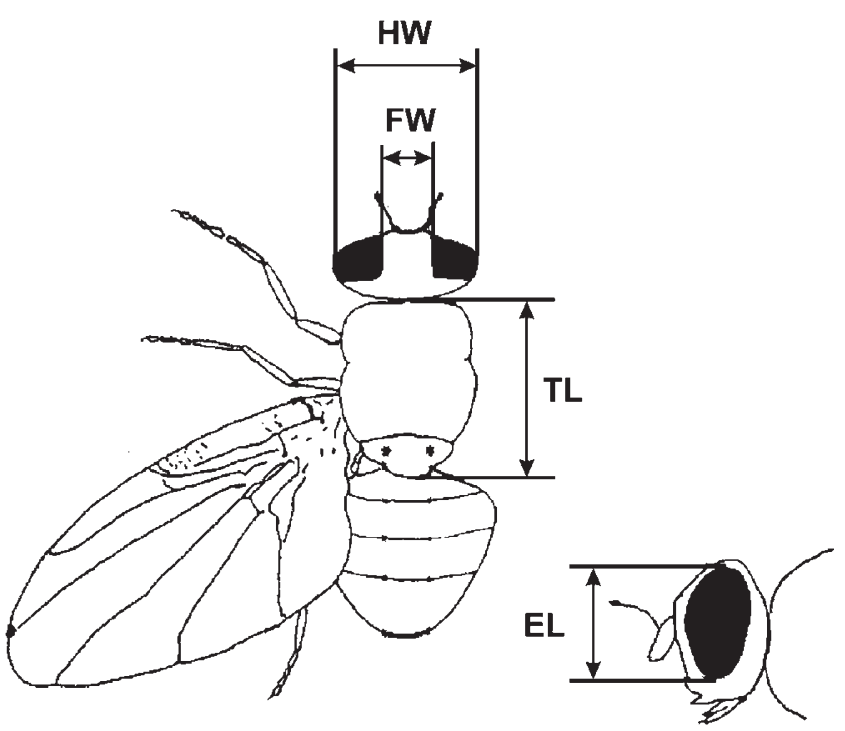

Figure 1 Description of measured traits. EL, eye length; FW, face width; HW, head width; TL, thorax length.

selection, because selection on a particular trait may produce indirect effects on the distribution of correlated characters (Lande and Arnold, 1983). To distinguish direct effects from spurious ones attributable to selection on correlated traits, a multivariate approach was applied as suggested by Lande and Arnold (1983). Two statistical alternative methods were applied. The first involved a classical multivariate analysis of variance (MANOVA). The second one consisted in principal component analysis (PCA) followed of logistic regression. PCA was used to identify major factors of variation within traits. To maximise the explained variance, the factors (PCs) were rotated using VARIMAX (Norry et al, 1999; Rodriguero et al, 2002). In order to evaluate if sexually selected traits are dependent on the female strain this analysis was applied independently for males mated with wild and with lab females.

The selection surface is useful in understanding the connection between traits and expected fitness (Phillips and Arnold, 1989; Brodie et al, 1995). It is obtained with the nonparametric regression technique of cubic splines (Schluter and Nychka, 1993), using the programme GLMS (version 15) kindly provided by D Schluter. This technique allows the production of a curve that gently fits to the set of observed data, minimising the overall prediction error (Schluter and Nychka, 1994). The smoothness of the spline curve is controlled by a nonnegative constant named $\lambda$. The estimate of selection surface assumes that selection act strongly on only one or a few phenotypic dimensions. The analysis defines a vector of traits (a 'projection' or 'direction') that experiences the strongest selection.

Male and female mating performance (proportion of mated flies of each strain) and assortative mating based on strain were evaluated by means of independence Chi square $\left(\chi^{2}\right)$ tests. A more detailed analysis, however, can be found in Cayol et al (1999). Assortative mating based on morphometric traits were estimated by means of Spearman rank correlation tests.

All statistical analyses were made with the software STATISTICA (Statistica Statsoft Inc, 1996).

\section{Results}

In both sexes all measured traits were, on average, higher for wild than for lab individuals (Table 1). The corresponding multivariate analysis of variance (MANOVA) indicates that size differences between strains are significant for both sexes (Wilks' Lambda $=0.545 ; P<0.001$ for males and Wilks' Lambda $=0.509 ; P<0.01$ for females). All traits contributed significantly or highly significantly to these differences (Table 2). The MANOVA also showed that successful and unsuccessful males differ for the morphometric traits independently of strain (Wilks' Lambda $=0.735 ; P<0.001)$. Such significant differences are caused by only two traits: TL and FW $(F=20.25 ; P$ $<0.0001$ and $F=49.33 ; P<0.0001$ respectively) (Table 2 ). All morphometric traits are positively and significantly correlated to each other, with $r$ ranging from 0.40 to 0.66 $(P<0.0001)$

PCA was applied to evaluate the variation among males mated with wild and lab females. Three PCs were obtained in each case that accounted for more than $90 \%$ of total variance (Table 3). For both female groups, only two axes showed significant association with mating success and they were mainly explained by TL and FW. Consistent with the results obtained in the previous MANOVA, the PC explained by TL was positively correlated with mating success, while the opposite occurred for the PC determined by FW. In both cases HW has a relatively high contribution to one of the $\mathrm{PC}^{\prime}$ s correlated with mating success. However, for males mated with wild females this trait has its highest loading (0.7) in the same PC as TL. Its contribution is relatively high and apparently is positively correlated with mating success. For lab females HW's highest loading (0.6) was obtained in the same PC as FW, showing a negative correlation with mating success.

Surface selection analysis (Figure 2a) mainly suggests directional selection, as can be seen in the monotonic increase of the surface, although a local maximum was observed. The contributions of the four traits to the best direction were not equal (Table 4). In consistence with previous analyses (MANOVA and PCA) the highest contribution corresponded to FW and TL and their effects had opposite signs. Additionally, the three-dimensional plot of mating success as a function of TL and FW (Figure $2 \mathrm{~b})$, shows that the maximum mating success is not placed in the edge of any trait distribution range.

The number of pairs collected for each mating combination and the proportion of unmated males were extracted from Cayol et al (1999). According to those data the average mating rate was $48.8 \%$. Lab females mated more than wild ones $\left(69 \%\right.$ and $31 \%$ respectively; $\chi^{2}=$ 156.914; $P \cong 0$ ). Lab males also mated more often than wild ones (54\% and $46 \%$ respectively), although this difference was not significant $\left(\chi^{2}=2.496 ; P=0.114\right)$. Finally, an excess (65:35) of homotypic mating (within strain) was observed $\left(\chi^{2}=60.184 ; P \cong 0\right)$, indicating positive assortative mating with respect to origin.

In relation to morphometric traits, a positive correlation between male and female in mating pairs was observed for TL $(r=0.211 ; P<0.01)$ when all couples were considered. Besides some other significant correlations between different size-related traits in males and females were observed: male TL and female HW $(r=$ 0.198; $P<0.01)$, and male FW and female TL $(r=0.146$; 
Table 1 Means \pm SE of morphometric traits $(\mathrm{mm})$ measured for both origins and both sexes, except for unsuccessful females

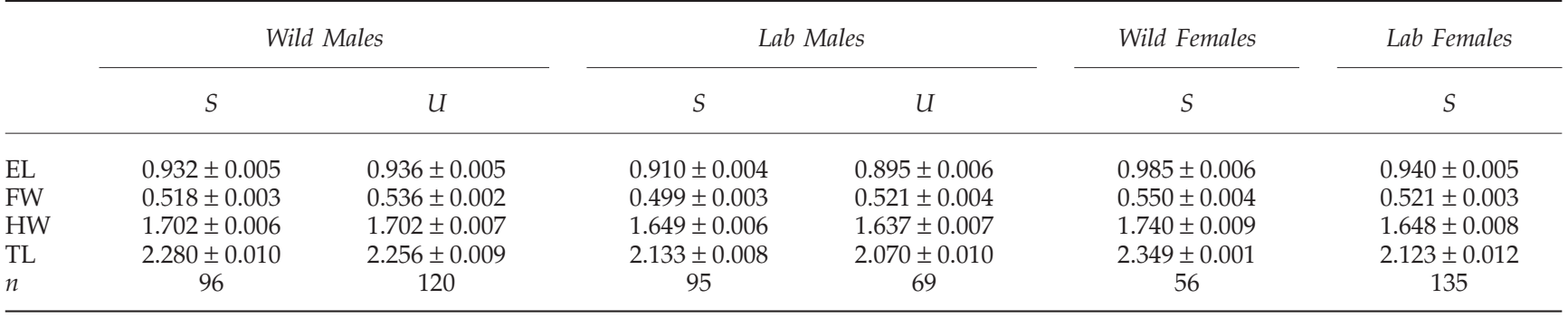

S: successful, U: unsuccessful.

Table 2 MANOVAs performed to test (a) morphometric differences among males attributable to strain and mating success, and (b) morphometric differences among females attributable to strain

\begin{tabular}{|c|c|c|c|c|c|c|c|}
\hline \multirow[t]{2}{*}{ Trait } & \multirow[t]{2}{*}{ Source } & \multicolumn{3}{|c|}{ (a) Males } & \multicolumn{3}{|c|}{ (b) Females } \\
\hline & & MS & d.f. & $F$ & MS & d.f. & $F$ \\
\hline & Strain & & & & & & \\
\hline EL & & 39.058 & 1 & $44.881^{* *}$ & 31.368 & 1 & $40.431^{* *}$ \\
\hline FW & & 21.970 & 1 & $27.845^{* *}$ & 31.305 & 1 & $40.333^{* *}$ \\
\hline HW & & 64.321 & 1 & $79.847^{* *}$ & 49.323 & 1 & $72.445^{* *}$ \\
\hline \multirow[t]{2}{*}{$\mathrm{TL}$} & & 163.935 & 1 & $307.177^{* *}$ & 83.068 & 1 & $165.381^{* *}$ \\
\hline & Mating Success & & & & & & \\
\hline EL & & 0.691 & 1 & 0.793 & & & \\
\hline FW & & 38.923 & 1 & $49.331^{* *}$ & & & \\
\hline $\mathrm{HW}$ & & 1.049 & 1 & 1.302 & & & \\
\hline \multirow[t]{2}{*}{$\mathrm{TL}$} & & 10.805 & 1 & $20.247^{* *}$ & & & \\
\hline & Interaction & & & & & & \\
\hline EL & & 1.223 & 1 & 1.405 & & & \\
\hline FW & & 0.711 & 1 & 0.901 & & & \\
\hline HW & & 0.003 & 1 & 0.004 & & & \\
\hline TL & & 0.979 & 1 & 1.834 & & & \\
\hline
\end{tabular}

**P $<0.0001$

Table 3 Factor loadings for morphometric traits in males mated with laboratory and wild females, logistic regression coefficient ( $\left.\beta^{\prime}\right)$ estimating the effects of each factor (PC) on mating success, eigenvalues and accumulated percentage of variance

\begin{tabular}{|c|c|c|c|c|c|c|}
\hline \multirow[t]{2}{*}{ Trait } & \multicolumn{3}{|c|}{ Males mated with wild females } & \multicolumn{3}{|c|}{ Males mated with lab females } \\
\hline & PC 1 & PC 2 & PC 3 & $P C 1$ & PC 2 & $P C 3$ \\
\hline EL & 0.279 & 0.220 & 0.931 & 0.937 & 0.219 & 0.268 \\
\hline FW & 0.159 & 0.938 & 0.207 & 0.174 & 0.942 & 0.178 \\
\hline HW & 0.710 & 0.564 & 0.151 & 0.304 & 0.627 & 0.581 \\
\hline TL & 0.901 & 0.093 & 0.301 & 0.248 & 0.204 & 0.924 \\
\hline Eigenvalue & 2.516 & 0.663 & 0.521 & 2.645 & 0.609 & 0.474 \\
\hline$\%$ variance & 62.896 & 16.569 & 13.026 & 66.126 & 15.219 & 11.856 \\
\hline Cumulative \% & 62.896 & 79.465 & 92.491 & 66.126 & 81.346 & 93.202 \\
\hline$\beta^{\prime}$ & $0.853^{\mathrm{a}}$ & $-0.706^{\mathrm{a}}$ & 0.009 & 0.075 & $-0.902^{\mathrm{a}}$ & $0.263^{\mathrm{b}}$ \\
\hline
\end{tabular}

Boldface values indicate the highest loadings of each trait on each component.

aP $<0.0001$.

${ }^{\mathrm{b}} P<0.05$.

$P<0.01)$. This result suggests some correlation between male and female size in mating pairs. However, when the analysis was performed independently within each type of mating (WW, WL, LW, and LL) the association between male and female size (mainly male and female TL) was not significant in any case (Table 5).

\section{Discussion}

Insect pest-management programmes that incorporate SIT require the knowledge of the natural mating behaviour of the pest species (Knipling, 1955; Cardé and Minks, 1995). In medfly, different authors (Churchill Stanland et 

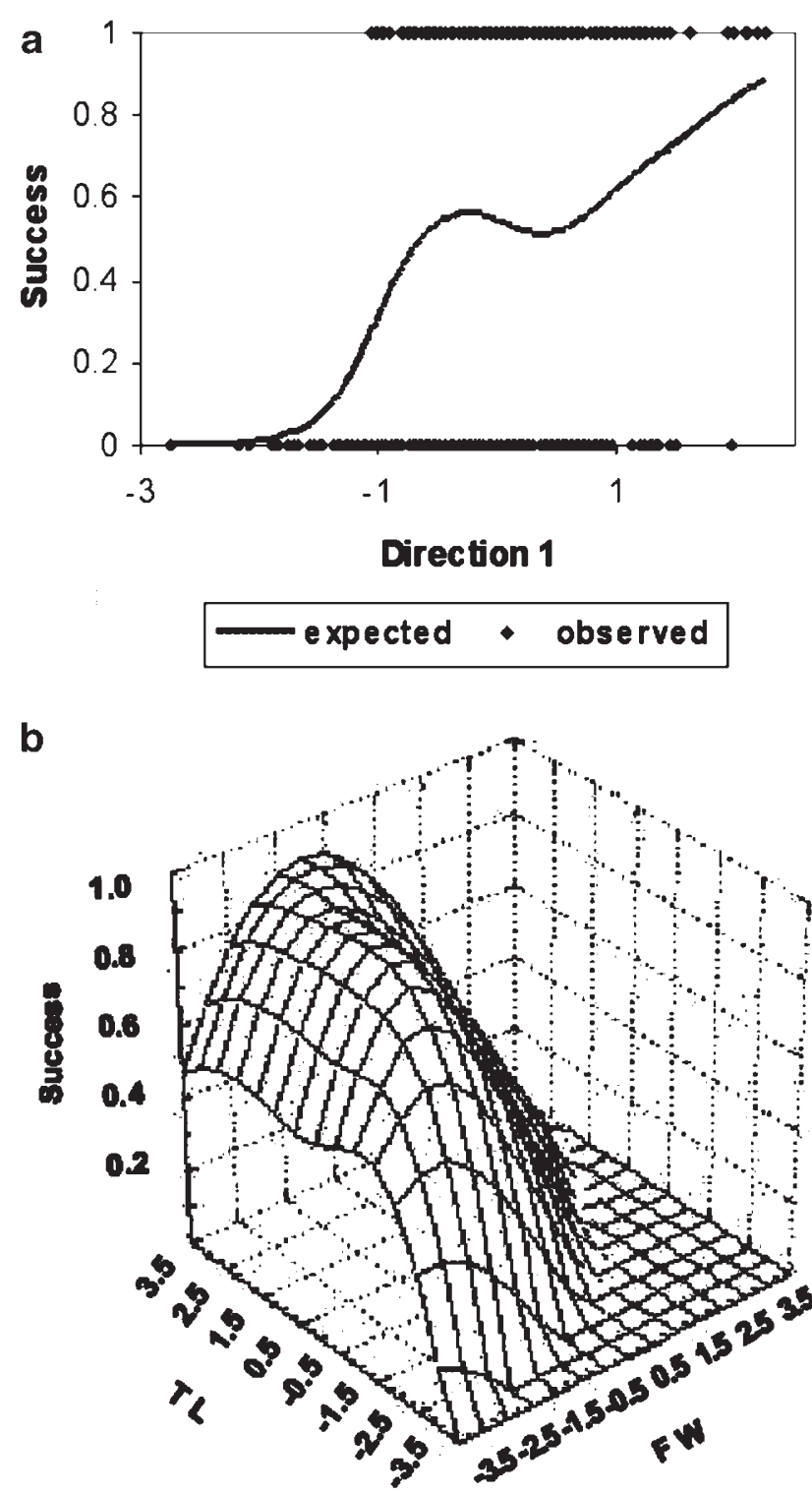

Figure 2 (a) Mating success of male medfly as a function of variation in the direction $a_{1}$ experiencing strongest selection. The direction is determined mainly by TL but also FW. Points are the original observations. (b) Mating success of male medfly as a function of face width (FW) and thorax length (TL). This graph gives a threedimensional perspective of the surface.

Table 4 The single direction $\mathrm{a}_{1}$ best explaining variation in mating success among male medflies

\begin{tabular}{lc}
\hline Trait & Direction $a_{1}$ \\
\hline EL & 0.095 \\
FW & $-\mathbf{0 . 4 6 1}$ \\
HW & 0.046 \\
TL & $\mathbf{0 . 8 8 1}$ \\
$\ln (\lambda)=-10$ & $n=380$ \\
\hline
\end{tabular}

Table 5 Spearman rank correlation coefficients $(r)$ for TL. Mating combination; first letter male, female second, $\mathrm{W}$ and $\mathrm{L}$ for wild and lab medfly respectively

\begin{tabular}{lcc}
\hline Mating & $r$ & $P$ \\
\hline L/L & -0.099 & 0.383 \\
L/W & -0.117 & 0.667 \\
W/L & -0.044 & 0.749 \\
W/W & -0.189 & 0.240 \\
\hline
\end{tabular}

al, 1986; Orozco and López, 1993; Blay and Yuval, 1997) have observed that successful males are, on average, larger than unsuccessful ones. Since these works were based on univariate approaches, the real target of sexual selection could not be clearly identified. Indeed, selection on unmeasured characters correlated with body size can lead to this interpretation (Lande and Arnold, 1983; Schluter and Nychka, 1994). In laboratory tests, Hunt et al (1998) observed that fluctuating asymmetry of the male sex setae is negatively selected. In addition, they observed that sex setae length does not differ between successful and unsuccessful individuals, but the relative length of this structure with respect to total body size is associated to copulatory success, suggesting the importance of analysing several traits simultaneously.

In quality control programs the competition tests that involve two male strains and only one female strain are referred as unisexual, while those involving males and females of both strains are defined as bisexual (see Cayol et al, 1999). Rodriguero et al (2002), using a multivariate approach, analysed the occurrence of sexual selection on size-related traits in a unisexual test where wild and lab males competed for mating with wild females in field cages. They measured eye (EL), wing (WL), and thorax (TL) lengths, and face (FW) and head (HW) widths and identified TL, EL and FW as possible targets of sexual selection. In the present work we used the same strains and conditions as in the experiment by Rodriguero et al (2002), but in this case both wild and lab females were released into the cages. This bisexual test allowed to evaluate the occurrence of assortative mating and possible female strain dependent differences in sexual selection patterns. The present results confirm that, for both wild and lab females, TL and FW are targets of sexual selection. The effects of EL in the present work were not significant, probably due to a significant interaction between day and success for this trait (data not shown). The results about HW are unclear but this trait might be female strain-dependent.

Norry et al (1999), working under laboratory conditions with the same wild population (Alto Valle, Patagonia) and removing experimentally the presence of male-male competition (allowing only intersexual selection to occur) inferred that head morphology was a good predictor of mating success, while body size (TL) had no apparent effect. Rodriguero et al (2002) suggested that the advantage of larger males in field cage experiments where male-male interactions can take place could be explained by the occurrence of intrasexual selection. Since C. capitata courtship involves head-to-head interactions between males and females (Féron, 1962; Calcagno et al, 1999, 2002), head morphology could account for intersexual selection. This may explain the effects of male sex setae 
asymmetry (Hunt et al, 1998), FW, and HW (Rodriguero et al, 2002, and this work). Alternatively, the advantage of larger males (TL) might be associated with activities prior to the initiation of the courtship. Larger males could exhibit higher mobility or ability to reach the hotspots in the tree before smaller males.

Analyses of the selection surface based on FW and TL suggest the occurrence of correlational selection on the multivariate phenotype as a by-product of directional selection acting on both traits separately and in the opposite direction. Because at least two of the original traits are represented in the linear combination $a_{1}$ (FW and TL), selection on it implies correlational selection on the multivariate phenotype. In fact, it could explain the local maximum observed in Figure 2a. Correlational selection is most easily visualised by plotting mating success against the two more important traits (FW and TL) (see Figure $2 b$ ). The consequence of positive covariation between characters selected in opposite directions would be the occurrence of a trade-off between FW and TL. This kind of selection favours particular combinations of two traits expressed together in the same individual, but may not affect the distribution of either trait alone (Endler, 1986). Although correlational selection was reported early in other species such as garter snakes (Brodie, 1992), song sparrows and human infants (Schluter and Nychka, 1994), the present paper documents, to our knowledge, the first evidence of this type of selection occurring in C. capitata.

Interestingly, FW and TL are identified as targets of sexual selection independently of the female strain considered. Since Norry et al (1999) detected that at least FW is selected intersexually, the similar conclusions obtained analysing wild and lab females suggest that the intense artificial selection produced during the mass-rearing process, coupled with genetic drift due to the initial small population size, has not affected intersexual selection (probably female choice) regarding this trait. This conclusion, however, cannot be extrapolated to other traits not included in the present analysis. In fact, some evidence of differences in mating preferences between wild and lab females arises from the higher mating rate of lab females. Moreover, in unisexual tests, lab males facing wild females only, showed reduced mating performance when compared to wild males (see Cayol et al, 1999, Rodriguero, 2002), while in the present analysis such difference could not be identified. Given that lab males exhibit deleterious effects as a by-product of irradiation (Favret et al, 1995; Calcagno et al, 2002) and that mass-rearing process may alter behavioural patterns (Boake et al, 1996; Liedo Fernández, 1997; Cayol, 2000) they might be chosen as partners by less-discriminating lab females (see Zapien et al, 1983; Kaneshiro et al, 1990). However, the present results suggest that lab females are not just less choosy, but they showed a stronger tendency to mate with massreared males than with wild males, consistent with other works in similar conditions (Guerra et al, 1983; Wong and Nakahara, 1978; Wong et al, 1984). Zapien et al (1983) observed a skewed mating pattern when considering the strain involved, despite the fact that both strains formed leks together. Furthermore, McInnis et al (1996), in a bisexual test, recorded a reduced number of heterotypic matings. This departure from random mating has been documented in another tephritid, the Mexican fruit fly, where mass-reared males partially substituted courtship

with an activity described as "mating aggression" (Moreno et al, 1991).

Changes in female preferences in mass-reared strains may have evolved together with changes in male courtship behaviour (Eberhard, 2000). Preliminary analyses suggest one possible case of such female-male co-ordination in a mass-reared strain in Costa Rica. While male courtship became shorter (Briceño and Eberhard, 1998), female discrimination against shorter courtship appears to have diminished in a Fisherian type of process (Briceño and Eberhard, 2000). This kind of process may explain assortative mating related to fly origin.

As an alternative to changes in the courtship behaviour, a possible cause for assortative mating might be associated with differences in the location of leks in the host. While wild males tend to join leks that are sited in the upper third of the tree, lab flies were located in central and lower thirds (Cayol et al, 1999). Most fights between males occur in the top of the tree (see Cayol et al, 1999) and it is conceivable that wild males displace lab males to the bottom of the tree. In addition, it was reported that irradiation does affect flight ability (Orozco and López, 1993). Therefore, irradiated males and females with reduced flight ability would tend to meet and mate at the bottom of the host tree while wild males and females would mate at the top.

In relation to morphometric traits, flies mate preferentially on the basis of TL. Therefore, females with greater thorax lengths will mate with males exhibiting the same condition. The remaining observed correlations could be explained in the basis of correlation among morphometric traits. These correlations however seem to be a byproduct of the positive assortative mating based on strain. In fact, when the analyses were performed for each mating type, the correlations became insignificant.

For obvious reasons related to the use of SIT, the massreared female has not been as thoroughly studied as the mass-reared male, however its behaviour has important consequences for quality control of mass-reared strains (Rössler, 1975). The vastly different requirements for biological success of colonisation in the wild vs. lab lead to divergent life history strategies and behaviours (Cayol 2000), and such factors lead to assortative mating in bisexual events. In fact, the modification of sexual behaviour (in males but in females too) which occurs during long-term rearing was shown to be the main reason for deterioration in mating competitiveness, rather than irradiation procedure per se (Liedo Fernández, 1997).

\section{Acknowledgements}

The authors wish to thank J Andino, A Asfennato, A Borges, H Jaldo, A Mongabure, E Parra, and M Villegas for the work done during field cage tests. We also thank people from the mass rearing facility BioKm 8 in Mendoza for providing the lab irradiated pupae. We are also grateful to E Willink and the team of the Estación Experimental Agroindustrial Obispo Colombres for their hospitality and F Norry for supplying the software for selection surface analysis. This work has been supported by International Atomic Energy Agency (IAEA Res. Contract No 1083/R1), the Universidad de Buenos Aires (PID TW09), the Agencia Nacional de Promoción Cientifica y Tecnológica (PICT 02269/97 and 06628/00) and the Con- 
sejo Nacional de Investigaciones Científicas y Técnicas (PIP 0722/98).

\section{References}

Blay S, Yuval B (1997). Nutritional correlates of reproductive success of male Mediterranean fruit flies (Diptera: Tephritidae). Anim Behav 54: 59-66.

Boake CRB, Shelly TE, Kaneshiro KY (1996). Sexual selection in relation to pest-management strategies. Annu Rev Entomol 41: 211-229.

Briceño RD, Eberhard WG (1998). Medfly courtship duration: a sexually selected reaction norm changed by crowding. Ethol Ecol Evol 10: 369-382.

Briceño RD, Eberhard WG (2000). Possible fisherian changes in female mate-choice criteria in mass-reared strain of Ceratitis capitata (Diptera: Tephritidae). Ann Entomol Soc Am 93: 343345.

Brodie III, ED (1992). Correlational selection for color pattern and antipredator behavior in the garter snake Thamnophis ordinoides. Evolution 46: 1284-1298.

Brodie III, ED, Moore AJ, Janzen FJ (1995). Visualizing and quantifying natural selection. Trends Ecol Evol 10: 313-318.

Calcagno GE, Manso F, Vilardi JC (2002). Comparison of mating performances for genetic sexing and wild type strains of Ceratitis capitata (Diptera: Tephritidae): field cage and video recording experiments. Fla Entomol 85: 41-50.

Calcagno GE, Vera MT, Manso F, Lux SA, Norry FM, Munyiri FN et al (1999). Courtship behavior of wild and mass-reared Mediterranean fruit fly (Diptera: Tephritidae) males from Argentina. J Econom Entomol 92: 373-379.

Calkins CO (1991). The effect of mass-rearing on mating behavior of Mediterranean fruit flies. In: Kawasaki K, Iwahashi O, Kaneshiro KY (eds) Proceedings of the International Symposium of the Biology and Control of Fruit Flies, Ginowan: Okinawa, pp 153-160.

Calkins CO, Webb JC (1983). A cage and support framework for behavioral tests of fruit flies in the field. Fla Entomol 66: 512-514.

Cardé RT, Minks AK (1995). Control of moth pests by mating disruption: successes and constraints. Annu Rev Entomol 40: 559-585.

Cayol JP (2000). Changes in sexual behavior and life history traits of tephritid species caused by mass-rearing processes. In: Aluja M, Norrbom A (eds) Fruit Flies (Tephritidae): Phylogeny and Evolution of Behavior, CRC Press: Boca Raton, Florida, pp 843-860.

Cayol JP, Vilardi JC, Rial E, Vera MT (1999). New indices and method to measure the sexual compatibility and mating performance of Ceratitis capitata (Diptera: Tephritidae) laboratory-reared strains under field cage conditions. J Econ Entomol 92: $140-145$.

Churchill-Stanland C, Stanland R, Wong TY, Tanaka N, McInnis DO, Dowell RV (1986). Size as a factor in the mating propensity of Mediterranean fruit flies, Ceratitis capitata (Diptera: Tephritidae) in the laboratory. J Econ Entomol 79: 614-619.

Darwin CR (1871). The Descent of Man and Selection in Relation to Sex. John Murray: London.

Eberhard WG (2000). Sexual behavior and sexual selection in the Mediterranean fruit fly, Ceratitis capitata (Dacinae: Ceratitidini). In: Aluja M, Norrbom A (eds) Fruit Flies (Tephritidae): Phylogeny and Evolution of Behavior, CRC Press: Boca Raton, Florida, pp 469-489.

Endler JA (1986). Natural Selection in the Wild. Princeton University Press: New Jersey.

Favret E, Lifschitz E, Manso F (1995). Esterilización de líneas autosexantes en la plaga de los frutales Ceratitis capitata Wied. (mosca del Mediterráneo). Mendeliana 11: 69-83.

Féron M (1962). L'instinct de reproduction chez la mouche Méditerranéenne des fruits (Ceratitis capitata) (Wiedemann) (Diptera: Tephritidae). Comportement sexuel. Comportement de ponte. Rev Path Vég D'Entomol Agr Fran 41: 1-129.
Franz G, Gencheva E, Kerremans P (1994). Improved stability of sex separation strains for the Mediterranean fruit fly, Ceratitis capitata. Genome 37: 72-82.

Guerra M, Orozco D, Schwarz A, Liedo P (1983). Mating competitiveness of mass-reared and sterilized Med-flies compared with wild flies. In: Cavalloro R (ed) Fruit Flies of Economic Importance, A. A. Bakema: Rotterdam, pp 113-119.

Hunt MK, Crean CS, Wood RJ, Gilburn AS (1998). Fluctuating asymmetry and sexual selection in the Mediterranean fruit fly (Diptera: Tephritidae). Biol J Linn Soc 64: 385-396.

Jones TM, Quinnell RJ, Balmford AS (1998). Fisherian flies: benefits of female choice in a lekking sandfly. Proc $R$ Soc Lond $B$ 56: 1651-1657.

Kaneshiro KY, Kanegawa KM, Whittier T (1990). Sexual selection in tephritid fruit flies and its implication in the SIRM. International Symposium on Fruit Flies of Economic Importance: 14-20 de October. Antigua, Guatemala.

Knipling GF (1955). Possibilities of insect control or erradication trough the use of sexually sterile males. J Econ Entomol 48: 459-462.

Lande R, Arnold SJ (1983). The measurement of selection on correlated characters. Evolution 37: 1210-1226.

Liendo Fernández P (1997). Comportamiento sexual de las moscas de la fruta y sus implicaciones para la Técnica del Insecto Estéril. In: Curso Regional sobre Moscas de la Fruta y su Control en Áreas Grandes con Énfasis en la Técnica del Insecto Estéril, IAEA: México, pp 79-87.

McInnis DO, Lance DR, Jackson CG (1996). Behavioral resistance to the Sterile Insect Technique by Mediterranean fruit fly (Diptera: Tephritidae) in Hawaii. Ann Entomol Soc Am 89: 739-744.

Møller AP (1994). Sexual Selection and the Barn Swallow. Oxford University Press, Oxford.

Moreno DS, Sánchez MS, Robacker DC, Worley J (1991). Mating competitiveness of irradiated Mexican fruit fly (Diptera: Tephritidae). J Econom Entomol 84: 1227-1234.

Norry FM, Calcagno GE, Vera MT, Manso F, Vilardi JC (1999). Sexual selection on male morphology independent of malemale competition in the Mediterranean fruit fly (Diptera: Tephritidae). Ann Entomol Soc Am 92: 571-577.

Orozco D, López RO (1993). Mating competitiveness of wild and laboratory mass-reared medflies: effects on male size. In: Aluja M, Liedo P (eds) Fruit Flies: Biology and Management, Springer: New York, pp 185-188.

Partridge L, Halliday TR (1984). Mating patterns and mate choice. In: Krebs JR, Davies NB (eds) Behavioral Ecology: an Evolutionary Approach: chap. 9, Blackwell Scientific Publications: Oxford, pp 222-250.

Phillips PC, Arnold SJ (1989). Visualizing multivariate selection. Evolution 43: 1209-1222.

Prokopy RJ, Hendrichs J (1979). Mating behavior of Ceratitis capitata on a field-caged host tree. Ann Entomol Soc Am 72: 642648.

Rodriguero MS, Vilardi JC, Vera MT, Cayol JP, Rial E (2002). Morphometric traits and sexual selection in Ceratitis capitata (Diptera: Tephritidae) under field cage conditions. Fla Entomol 85: 143-149.

Rössler Y (1975). Reproductive differences between laboratoryreared and field-collected populations of the Mediterranean fruit fly, Ceratitis capitata. Ann Entomol Soc Am 68: 987-991.

Rössler Y (1979). The genetics of the Mediterranean fruit fly: white pupa mutant. Ann Entomol Soc Am 72: 231-235.

Schluter D, Nychka D (1993). Cubic spline estimate of fitness surface using projection pursuit regression. Version 1.2.

Schluter D, Nychka D (1994). Exploring fitness surfaces. Am Nat 143: 597-616.

Statsoft Inc (1996). Statistica 5 for Windows (Computer Program Manual). Tulsa, OK.

Webb JC, Calkins CO, Chambers DL, Schwienbacher W, Russ K (1983). Acoustical aspects of behavior of Mediterranean fruit 
fly, Ceratitis capitata: analysis and identification of courtship sound. Ent Exp Appl 33: 1-18.

Whittier TS, Kaneshiro KY, Prescott LD (1992). Mating behavior of Mediterranean fruit fly (Diptera: Tephritidae) in a natural environment. Ann Entomol Soc Am 85: 241-218.

Whittier TS, Nam FY, Shelly TE, Kaneshiro KY (1994). Male courtship success and female discrimination in the Mediterranean fruit fly (Diptera: Tephritidae). J Insect Behav 7: 159170.

Wong TTY, Kobayashi RM, Whitehand LC, Henry DG, Zadig DA, Denny CL (1984). Mediterranean fruit fly (Diptera:
Tephritidae): mating choices of irradiated laboratory-reared and untreated wild flies of California in laboratory cages. $J$ Econ Entomol 77: 58-62.

Wong TTY, Nakahara LM (1978). Sexual development and mating response of laboratory-reared and native Mediterranean fruit flies. Ann Entomol Soc Am 76: 51-55.

Zapien G, Hendrichs J, Liedo P, Cisneros A (1983). Comparative mating behavior of wild and mass-reared steril medfly Ceratitis capitata (Wied.) on a field cage host tree II. Female mate choice. In: Cavalloro R (ed) Fruit Flies of Economic Importance, A. A. Bakema: Rotterdam, pp 397-409. 